\title{
ASSESSING ENTREPRENEURIAL ORIENTATION IN THE INSTRUCTIONAL SETTING: TESTING A MODEL
}

\author{
Jean-Charles Cachon and Barry Cotton, Laurentian University
}

This research was funded in part by a Social Sciences \& Humanities Research Council of Canada block grant.

\section{ABSTRACT}

This paper reports the initial investigation of the possibility of identifying an entrepreneurial orientation among subjects who have undergone a verture identification and creation experience. The basis for the development of the measurement model were characteristics identified from the literature as forming the emerging entrepreneur paradigm

The purpose of the longitudinal research is to establish a methodology for the identification of people possessing entrepreneurial potential and whose further development could then be encouraged.

Variables in the model which proved to be predictors of entrepreneurial orientation included Locus of Control which is a very strong entrepreneurial orientation. Attitude Towards Risk proved to be a predictor of a general interest in entrepreneurial activities, supporting findings in the literature. Significantly, a new variable was identified out of scales measuring Personal Objectives (PO). A strong link was found bet ween the nature of personal skill advantages, objectives and interests fulfilled during the experimental project and entrepreneurial orientation.

\section{SOMMAIRE}

Cet article rend compte de travaux initiaux sur la détermination de l'esprit d'entreprise de sujets qui ont fait une expérience supposant la prise de risques et un recours à la création. Le modèle de mesure a été élaboré à partir de caractéristiques trouvées dans les livres pertinents sur ce qui constitue l'archétype de l'entreprneur en puissance.

La recherche longitudinale vise à trouver des méthodes pour déterminer les personnes douées d'un esprit d'entreprise dont on peut favoriser le développement.

Parmi les variables du modèle qui se sont révélées être des indices d'esprit d'entreprise, figure le "lieu géométrique d'autorité", un critère très important. Il s'est avéré que l'attitude face au risque était un indice d'intérêt général pour les activités reliées à l'esprit d'entreprise, ce qui corrobore les constatations des écrits sur la question. Une nouvelle variable a été dégagée des échelles qui mesurent les objectifs personnels (OP). On a, en effet, découvert un lien étroit entre les aptitudes, les objectifs et les intérêts personnels concrétisés au cours du projet expérimental, d'une part, et l'esprit d'entreprise, d'autre part.

\section{PURPOSE OF RESEARCH}

Over the past decade, an extensive volume of literature has evolved centring upon the identification of the characteristics of entrepreneurs and the development of potential entrepreneurs (1). A greater proportion of the research focusses upon the physical and socio-psychological characteristics of subjects identified as entrepreneurs. Although a number of characteristics are still in dispute-religion, education, need for power, being innovative, etc- - a number of aspects are generally acknowledged as being constituent socio-psychological dimensions of the entrepreneur's make up. These include locus of control,(2),(3); moderate risk-taking propensity (4),(5),(6); tolerance of ambiguity (7),(8); and need for achievement (9),(10). 
A second body of research focusses on issues relating to the development of potential and existing entrepreneurs. The research into the developmental aspects has, in turn, focussed upon three areas. These are the economic importance of entrepreneurs, their activities and training needs; the role of government and the higher-education institutions in the development of entrepreneurs; and pedogogical approaches (cases, projects, action learning) and curriculum content (motivational/supportive vs. functional).

The development of a business plan as a course project is currently the closest pedogogy to action-learning activities involving actual student participation in the entrepreneurial milieu through innovation centres (11); part-time employment (12); or incubators (13). It appears that, at the learning stage, some form of self-motivated actionoriented or role-playing exercise is needed to develop an interest in venture creation and thus self-employment among subjects.

This view is supported both by Gibb \& Scott (14) \& Clark et al. (15) who respectively report positive attitude changes towards self-employment among small-business education attendees in Northern England and students creating businesses after graduation. Further evidence is put forward by Cotton \& Cachon (16) who, in measuring the effectiveness of a business-development project, point to the subsequent creation of business enterprises by participants.

Three important questions arise from this discussion. First, can distinguishing characteristics be identified in subjects who display such positive attitudes or attitude changes? Second, do the characteristics "fit" with the emerging entrepreneur paradigm? Third, how can the identification of these characteristics in individuals assist instructional institutions to help people cross the gap between simulated entrepreneurial activities in the learning setting and obtaining more than just a passing appreciation of the physical and mental activities involved in the actual identification of an opportunity and the start-up of a new venture?

The purpose of the study reported here is to verify if a model of entrepreneurial characteristics, constructed from those identified in the literature, would be appropriate to predict an individual's orientation towards entrepreneurship, and thus potential as a self-employed businessperson.

Data in Table 1 represent a classification into dependent and independent variables of entrepreneurial characteristics identified in the literature. If these characteristics are accepted as forming an entrepreneurial paradigm, we can then hypothesize that they might allow us to (a) predict the level of entrepreneurial orientation of subjects and (b) develop, and test for effectiveness activities which are entrepreneurial in nature. These are activities which, if integrated as component parts of educational courses, can lead to the further development of entrepreneurial orientation.

\section{MEASUREMENT OF ENTREPRENEURIAL ORIENTATION}

In the light of the discussion above, nine key variables are identified in Table 1, one dependent and eight independent variables.

\section{Dependent Variable}

Entrepreneurial orientation (EO), the dependant variable in the model, represents the current attitude of the students towards certain aspects of the testing medium, a venturedevelopment project. They included perceptions of the chances of the success of the proposed venture, interest in continuing studies of, and or participating in entrepreneurial activities, the perceived importance of such an experience as part of the program and the importance of the activity for personal achievement. A subject displaying an aboveaverage score on this scale may be considered as having a stronger entrepreneurial orientation, (i.e., being more interested in entrepreneur-type activities than subjects with below- 
Table 1

Model of Individual Student Entrepreneurial Orientation

VARIABLES

Dependent Variables:

No. Items

in Scale

$\mathrm{EO}=$ Entrepreneurial Orientation

(20 Items)

Independent Variables (Predictors):

INDIVIDUAL -

$\mathrm{LC}=$ Locus of Control Measure

(Neal \& Seeman, 1964)

(07 Items)

$\mathrm{CD}=$ Choice-Dilemma Procedure

(Kogan \& Wallach, 1964)

(12 Items)

$\mathrm{RA}=$ Perceived Attitude Toward Risk-Taking

(08 Items)

PO $=$ Personal Objectives Perceived as Being

Fulfilled by the Business

Development Project

(14 Items)

PS $=$ Personal Skills including Previous Experience

Family Influences and Role Models

(08 Items)

$\mathrm{PD}=$ Perceived Personal Level of

Dedication towards the Business

Development Project

(08 Items)

$\mathrm{TU}=$ Perceived Effectiveness of Level of Tutor Support

(05 Items)

GROUP

GS $=$ Perceived Cohesion \& Purposefulness of

Group Activities During Business

Development Project

(16 Items)

CONTROL VARIABLE (Mediator):

$\mathrm{MF}=$ Gender

46 
average scores). A strong EO score subject would also indicate that personal benefits received during the experiment were higher than the level indicated by lower scorers.

\section{Independent Variables}

Studies of ent repreneurship generally approach the subject on a individual basis, the assumption being that any activity associated with venture creation is rooted in the individual. Consequently, seven of the eight independent variables represent personal attributes which will serve as predictors of an entrepreneurial orientation. The scales developed to measure the at tributes are attitudinal in nature and each consists of between five and 16 items.

The eighth independent variable represents the influence of aspects of the subjects project group. Limited resources dictated the use of small groups of subjects in the completion of the project, rather than individual work.

The seven personal-attribute independent variables include two established measurement procedures. First, the Neal and Seeman (17) Powerlessness Scale to measure Locus of Control (LC Scale, Table 1) and the Kogan \& Wallach (18) Choice-Dilemma Procedure to measure attitude towards risk (CD Scale, Table 1). The latter has been designed as a semi-projective instrument to measure risk-taking attitudes in situations involving a third party. An additional scale was developed and included to measure attitudes towards personally risky social situations (RA Scale, Table 1), the rat ionale being that ent repreneurs will not only display a propensity for risk-taking in business situations, but also in personal life.

Other personality variables are designed to measure the personal involvement of the subject in the project (PO Scale, PS Scale PD Scale and TU Scale, Table 1), the rationale being that if the project was perceived as being important towards the attainment of personal goals (PO Scale, Table 1), and if the student had a perception of having had good personal skills to bring to the development of the project (PS Scale, Table 1) and a high level of dedication to its successful completion (PD Scale, Table 1), then he/she would also tend to show a higher than average score on the EO Scale.

Finally, the perception of a subject of the satisfactory or unsatisfactory levels of supportive direction by the tutor was measured (TU Scale, Table 1), the rationale being that those subjects perceiving an unsatisfactory level of support would also display a lower entrepreneurial orientation.

The GS Scale (Table 1) was developed to measure the individually perceived impact of group activities, interactions and decision-making procedures, on the outcome of the project.

\section{CONDUCT OF THE EXPERIMENT}

Two hypotheses were developed.

1. An above-average entrepreneurial orientation indicated by the 20 -item EO scale will be positively related to a perception by these individuals of having:

- a higher tendency to take risks (CD \& RA Variables)

- having an internal locus of control (LC Variable)

- a higher level of dedication to the project (PD Variable) and personal skills (PS Variable)

- developed a strong personal interest in the entrepreneurial experiment (PO Variable)

- low need for tutorial support (TU Variable)

- a perception of group interactions and cohesiveness as not being related to their interest in entrepreneurial activities (GS Variable).

2. A below-average entrepreneurial orientation indicated by the 20 -item EO Scale will be positively related to a perception by the subjects of having: 
- an external locus of control (LC Variable)

- a greater need for tutorial support (TU Variable)

- a greater need for group interaction and cohesiveness (GS Variable).

While the relationship between the entrepreneurial orientation of these individ uals and the other explanatory variables would be weak. This would be indicated by:

- a lower perception of a tendency to take risks (CD and RA Variables)

- a lower level of dedication to the project (PD Variable)

- a perceived lower level of personal skills (PS Variable)

- the perception of low level of personal interest in the entrepreneurial experiment (PO Scale).

Subjects were 88 third-year undergraduate business students formed into groups of three to five students per group. The mean age was 22 years, with a range from 20 to 30 years; 48 of the subjects were male, 40 female. The subjects comprised the 3 rd-year population of students for 1985/1986 at Laurentian University's School of Commerce, Ontario, Canada.

The project was imposed as a required component in the Marketing Management course assessment, a compulsory course required by all students in the B.Comm. program.

Students were required to:

1. Identify a business opportunity for which there was a perceived need.

2. Submit, five weeks after the start date, a detailed business plan to their supervisor, at the same time making a formal presentation of their case to the supervisor and a panel of students.

Only two constraints were placed on students. The first involved the time constraints imposed both by semester length and those which might typically be experienced in an actual business situation. The second constraint involved the level of venture-capital funding potentially available. This ranged from $\$ 2000$ to $\$ 5000$, depending on the anticipated life of the proposed venture. This was not an inflexible constraint, providing that secondary sourcing was specified and was fully justified in the planning. Subjects were informed that the outcome of the project would depend on the originality/innovativeness/workability of the concept, and the thoroughness and professionalism of the final report and its contents.

This was the limit of instructor input. The intention here was to remove the project as far from the structured classroom environment as was possible, thereby increasing uncertainty and risk.

The test of the model involved a questionnaire administered in a classroom setting one week after the report submission. All items comprising the scales measuring the nine variables set out in Table 1 were included.

\section{DATA ANALYSIS}

Reliability procedures were conducted by using the SPSSX's package split-half procedure, which yields a Spearman-Brown reliability coefficient by comparing items in each separate scale. involved.

At this stage, validity computations were not possible as only one sample was

The results show stable levels of reliability for the LC and DC scales, as expected. Among the seven remaining scales, only four were showing acceptable levels of reliability the EO, PO, RA and TU scales. This suggested that the three remaining scales should not be retained for further analysis.

Table 2 contains the means and standard-deviations for each of the variables retained for a nalysis. 
Table 2

Mcans \& Standard Deviations

\begin{tabular}{ccrrrrr} 
& \multicolumn{2}{c}{ Population } & \multicolumn{2}{c}{ Low EO Scores } & \multicolumn{2}{c}{ High EO Scores } \\
Variable & Mean & Std.D. & Mean & Std.D. & Mean & Std.D. \\
\hline EO & 769.8 & 268.4 & 583.1 & 157.7 & $1004.5^{*}$ & 179.1 \\
PO & 567.1 & 166.4 & 507.1 & 166.6 & 642.4 & 133.7 \\
RA & 179.2 & 121.9 & 157.2 & 102.5 & 207.0 & 139.1 \\
TU & 165.5 & 85.9 & 167.2 & 77.0 & 163.3 & 96.9 \\
CD & 522.2 & 142.2 & 506.7 & 126.0 & 541.5 & 159.3 \\
LC & 3.5 & 1.8 & 3.3 & 1.9 & 3.8 & 1.8 \\
(*)Significant difference between High vs. Low & & & & & \\
Scorers at $p<=0.05$ & & & & &
\end{tabular}

The data contained in Table 2 reveal that if the total sample is split at the mean level of 769.8 , the Low-or-Equal to Mean segment shows a significantly lower mean score on the EO Scale than the Higher-than-Mean scoring segment. This is not the case for the other variables tested.

The analysis detecting whether the EO scale and the independent variables scales were correlated (Pearson Product-Moment Method) yielded the following results:

- For the total population $(\mathrm{N}=88)$, the variable Perceived Personal Objectives (PO) had the strongest relationship to the Entrepreneurial Orientation (EO) variable.

- The Perceived Attitude to Risk (EA) and Choice Dilemma (CD) variables are also significantly correlated to the dependent variable. It is noteworthy that these same two variables were significantly correlated to the $P O$ variable as was the RA variable. However, the relationship was not sufficiently significant to suggest multicolinearity among independent variables.

Correlation tables were also computed to identify possible differing patterns between below- and above-average scorers on the EO Scales. The results were as follows:

- Generally, the correlations were significantly stronger for the higher-scorer group compared to the lower-scorer group.

- The correlation between the CD and PO variables observed with the total population did not appear in the subgroups.

The comparison between the two subgroups suggests that:

- Correlations with the dependent variable follow a different pattern among below-vs. above-mean score subjects. Lower scorers show a stronger correlation with the TU variable while higher scorers show a stronger correlation with the PO, RA and CD variables.

- The correlation between the two variables RA and CD is stronger among higher scorers.

- Higher scorers show a significant positive relationship between the TU and the LC variables, suggesting that the perception of instructor support is more positive among internal locus of control students.

Based on the preceding analyses, further multivariate analyses using the forward 
inclusion-regression method were conducted. Most of the analyses were done on all subjects as well as on sub-groupings relevant to the hypotheses to be tested. The EO scale scores rcpresented the dependent vector, while the scores obtaincd on the fivc independent variables retained after the reliability analysis represented the matrix of predictors.

A first regression on all subjects and all variables resulted in the $P O$ variable emerging as the major predictor of entrepreneurial orientation. The TU, CD and RA variables had a minor effect. This result indicates that, overall, the subjects tend to link the outcome of the venture-capital experiment as expressed by the EO variable (in terms of their interest for entrepreneurial activities), to the degree of interest they already had in doing the project itself. This leads to the conclusion that a positive interest in the activity was necessary to possess a positive feeling at the end.

Analyses were conducted to evaluate possible differences between segments classified according to their score on the dependent-variable EO scale. The mean score (total of the 20 items in the scale) of 769.8 was used for the Above -/Equal - or BelowMean classification rule. When comparing low-vs. high-scorers on the EO scale, the variable TU is the major predictor in the low-scoring segment and the RA variable is the most significant predictor of the high-scorers on the dependent variable scale. Such a difference is of interest in relation to the hypotheses of this study. While it fails to establish all the hypothesized relationships it leads to the conclusions that: 1. High-scorers on the EO scale show a significantly strong relationship between their attitude towards risk and their entrepreneurial orientation, a result which is consistent with other findings among entrepreneur researchers, and, 2. Low-scorers significantly relate tutorial support to entrepreneurial orientation, which appears consistent with the assumption that a person less interested in the experiment at the beginning shows a tendency to depend more on instructor guidance to complete it rather than on their own personal motivation and drive.

To pursue in more detail the study of the difference between low and high scorers on the EO variable scale, a discriminant analysis was conductd with low/high EO variable scorer as the group variable and Personal Objectives (PO), Risk Attitude (RA), Tutorial Support (TU), Locus of Control (LC) and Choice Dilemma (CD) as explanatory variables.

The results show that Personal Objectives and Locus of Control formed the discriminating function. This, however, only accounted for 23 per cent of the variance in the low-/high-scorer grouping. The correct classification rates show Personal Objectives as the strongest discriminating variable thus confirming this aspect of the hypotheses. The presence of Locus of Control as a second discriminating variable supports the hypotheses of this study, but fails to confirm results regarding the role of risk and tutorial support as potential discriminating variables. This discrepancy is mostly because the correlations between the predictors and the dependent variable are generally low in the group.

\section{CONCLUSIONS}

The general conclusions of this study must be regarded with caution since most of the scales that have been used are new instruments whose validities are still to be measured. It must also be noted that the two hypotheses of this study could not be fully tested as a result of the elimination of three scales from the analysis because of an unacceptable level of reliability.

The Pearson correlation and regression analyses support in part the two hypotheses by clearly identifying the Attitude Toward Risk variable as being related to an Entrepreneurial Orientation, while subjects being less entrepreneur-oriented tended to show stronger relationships with Tutorial Support. The relationship found here between 
risk and our EO variable is important as it concurs with previous findings (19), (20), (7).

A further finding supports a conclusion by Brockhaus (4) that risk-taking propensity as measured with the Kogan-Wallach Choice Dilemma instrument is not significantly different among entrepreneurs (or, in this case, potential entrepreneurs) and the general population.

While Locus of Control was hypothesized as being a strong predictor of an Entrepreneurial Orientation (2),(21) another variable, attitudinal and self-related in nature, appeared as a strong predictor. Measured with the PO scale, it encompasses the personal advantages, objectives and interests a subject feels he/she was fulfilling during the project. A subject displaying a strong score on this scale would have the feeling of having put a strong personal interest in the project, largely in order to reach personal goals in terms of self-esteem, achievement, pride in playing an important role and leadership within his/her group. This finding is in line with studies linking Need for Achievement with Entrepreneurial Orientation.

Finally, Locus of Control appears as a discriminating variable still inconjunction with Personal Objectives, between the two groups. This confirms the hypotheses and reinforces the conclusion that the EO variable measurement scale might be a useful tool, under certain conditions, to evaluate the entrepreneurial orientation of subjects.

These findings are, however, tentative and further research is required to achieve a higher degree of stability in the scales measuring the variables that form the model. Validity measures are also required to ensure replicability.

The reliability measures reported above also suggest some differences according to sex. This aspect could prove to be an important mediator, thus possibly leading to the construction of two distinctive groups of scales.

\section{REFERENCES}

1. Gasse, Y. (1985) "L'entrepreneurship: une stratégie de recherche et d'intervention pour le développement". Petites et Moyennes Organisations, 1, 5, 8 to 24, 44.

2. Borland, C. (1975), Locus of Control, Need for Achievement and Entrepreneurship. Austin, TX: University of Texas.

3. Panday, J., N. B. Tewary, (1979). "Locus of control and achievement values of entrepreneurs". Journal of Occupational Psychology, 52, 2, 107 to 111.

4. Brockhaus, R. H. (1980), "Risk Taking Propensity of Entrepreneurs", Academy of Management Journal, 23, 3, 509 to 520.

5. Jacobowitz, A., D. Vilder, (1982). "Characteristics of entrepreneurs: Implication for vocational guidance", Vocational Guidance Quarterly, 30, 3, 252 to 257.

6. Schwer, K., U. Yucelt, (1984). "A study of risk-taking propensities among small business entrepreneurs and managers: an empirical evaluation". American Journal of Small Business, 8, 3, 31 to 40.

7. Hull, D. L., J. H. Bosley, G. Udell, (1980). "Renewing the hunt for the heffalump: identifying potential entrepreneurs by personalit y characteristics". Journal of Small Business Manager, 18, 1, 11 to 18.

8. Gasse, Y. (1982). “L'entrepreneur moderne: attributs et fonctions". Revue Internationale de Gestion, 7,4.

9. McClelland, D. C. (1961), The Achieving Society. New York, NY: Van Nostrand.

10. Lachman, R. (1980). "Toward measurement of entrepreneurial tendencies", Management International Review, 20, 2, 108 to 116.

11. Colton, R. M., G. G. Udell, (1976). "The National Science Foundation's Innovation Centers: An experiment in training potential entrepreneurs and innovators", Journal of Small Business Management, 14, 2, 11 to 20. 
12. Maxon, R. C., K. E. Stone, (1977), “A strategy for developing effective management training". Journal of Small Business Management, 15, 3, 9 to 14.

13. Allen, D. N., S. Rahman, (1985). "Small business incubators: a positive environment for entreprencurship." Journal of Small Business Management, 23, 3, 121022.

14. Gibb, A., M. G. Scott, (1984). Entrepreneurship and Higher Education. Part 1. Durham: Durham University Business School, $93 \mathrm{p}$.

15. Clark, B. W., C. H. Davis, V. C. Harnish, (1984). "Do courses in ent repreneurship aid in new venture creation?" Journal of Small Business Management, 22, 2, 26 to 31.

16. Cotton, G. B., J. C. Cachon, (1986). "Entrepreneurial training effectiveness: developing measures for undergraduate business-school students". Sudbury, Canada: School of Commerce, Laurentian University.

17. Neal, A. G., M. Seeman, (1964), "Organizations and Powerlessness: A Test of the Mediation Hypothesis". American Sociological Review, 29, 216 to 226.

18. Kogan, N., \& M. A. Wallach, "Risk Taking", Holt, Rhinehart \& Winston, New York, N.Y., 1964.

19. Palmer, M. (1971). "Application of psychological testing to entrepreneurial potential". California Management Review, 13, 3, 32 to 38 .

20. McMullan, W. E., W. Long, (1983). "An approach to educating entreprencurs". Journal of Small Business Canada, 1, 2, 32 to 37.

21. Rotter, J. B. (1966). "Generalized expectancies for internal versus external control of reinforcement". Psychological Monographs, 80, 1 to 27. 